\title{
ФАКТОРЫ РАЗВИТИЯ ПОТЕНЦИАЛА РОССИЙСКОГО ЭКСПОРТА УСЛУГ 1
}

\section{FACTORS OF DEVELOPING THE POTENTIAL OF RUSSIAN EXPORT OF SERVICES}

\section{E. Sokolova \\ Sh. Guseinov \\ N. Toropova}

Summary: The article analyzes the domestic services market, in particular, its export component, examines the features and development potential of the Russian services market, substantiates the main problems and factors affecting trade in services. Based on the determination of the factors influencing the world market for services, the current trends in the development of the world market for services are identified. As a result of the study, a number of organizational and regulatory measures were proposed to increase the potential of Russian exports of services.

Keywords: world market of services, export of Russian services, potential, factors of influence, promising directions.

\author{
Соколова Елизавета Сергеевна \\ Д.э.н., Финансовый университет при Правительстве \\ Российской Федерачии \\ sokolovaes15@mail.ru \\ Гусейнов Шахин Рагим оглы \\ Д.э.н., Московский государственный институт \\ международных отношений МИД России \\ 9585015@mail.ru \\ торопова Наталья Валентиновна \\ К.э.н., в.н.С., Финансовый университет при \\ Правительстве Российской Федерачии \\ NToropova@fa.ru
}

Аннотация: В статье проведен анализ отечественного рынка услуг, в частности, его экспортная составляющая, рассматриваются особенности и потенциал развития российского рынка услуг, обоснованы основные проблемы и факторы, влияющие на торговлю услугами. На основании определения факторов влияния на мировой рынок услуг, выявлены современные тенденции развития мирового рынка услуг. В результате исследования предложен ряд мер организационного и нормативно-правового характера, направленных на повышение потенциала российского экспорта услуг.

Ключевые слова: мировой рынок услуг, экспорт российских услуг, потенциал, факторы влияния, перспективные направления.

зированы факторы влияющие на мировой рынок услуг и потенциал российского экспорта услуг в условиях распространения пандемии коронавируса, карантинных мер и связанных с ними экономических последствий.

Проведенный анализ научной литературы, позволил обобщить и систематизировать выводы, сделанные авторами по итогам исследований. Так, достаточно интересную гипотезу о сочетании ресурсного и процессного подходов к пониманию экспортного потенциала национальной экономики выдвигают авторы исследования, посвященного теоретическим подходам к исследованию экспортного потенциала национальной экономики [1], вопросы целесообразности применения диверсификации, преимуществ географической структуры, более полное использование импортного потенциала развивающихся стран и системы «коммерческого присутствия» обсуждаются в работе Шуйского В.П. [2]. Кроме того, анализируя современные тенденции мирового рынка услуг, авторы Федорова О.А., Скорлупина Ю.О., Федерова М.М. [3] в статье обосновывают факторы устойчивого сохраоткрытых источников информации, авторами проанали-

Статья подготовлена в рамках выполнения Государственного задания 2020 г. по теме: «Повышение конкурентоспособности российских услуг на глобальных рынках и формирование в Российской Федерации привлекательных условий для экспортеров услуг и инвесторов». 
нения отрицательного сальдо баланса услуг и обосновывают трудности устранения этих факторов, предлагая инструменты реформирования структуры экспорта услуг и перспективные направления для роста объема экспорта услуг. Актуальные стороны экспорта услуг малых и средних предприятий на мировом рынке, рассматривающие инновационную стратегию, стратегию экспортного маркетинга и самостоятельную бизнес-стратегию компании, а также влияние этих составляющих на показатели экспорта и конкурентоспособности на международном рынке анализируются в работе авторов Сафари, А. и Салех, А.С. [4]

Мировой рынок услуг в современной экономике становится одной из основных составляющих мирового рынка торговли, пребывая в стадии стремительного развития, в России он сохраняет устойчивую тенденцию преобладания над ростом объемов рынка товаров.

На мировом рынке экспорта услуг наибольший объем от общего экспорта услуг занимают коммерческие услуги, туристические, прочие бизнес-услуги, оплата за пользование интеллектуальной собственностью, финансовые услуги, услуги по транспортировке, телекоммуникационные и т.д. Такая же тенденция наблюдается и в экспорте российских услуг. Происходящие изменения в современной мировой экономике находятся в тесной взаимосвязи с процессами развития экспорта не только товаров, но и в первую очередь, как показывает практика, экспорта услуг, принуждая оперативно подстраиваться под тенденции и изменения внешней среды.

Очевидно, что потенциал российского экспорта услуг является одним из значимых показателей уровня развития экономики страны и ее конкурентоспособности на мировом рынке. По мнению исследователей тенденций мирового рынка [5], вопросы теоретического и практического анализа потенциала экспорта услуг, а также факторов, влияющих на его развитие, становятся приоритетными направлениями государственной экспортной политики и задач устойчивого развития. В связи с этим, можно сказать, что в сегодняшних экономических и политических реалиях ведущим фактором, влияющим на увеличение потенциала российского экспорта услуг, является реализация мер государственной поддержки. Утвержденная в 2019 году Правительством РФ Стратегия развития экспорта услуг до 2025 года (далее - Стратегия), обозначила приоритетные направления развития потенциала российского экспорта услуг.

Для реализации плана мероприятий по реализации Стратегии уже на сегодня в рамках межотраслевых мер принято постановление Правительства РФ от 17.04.2020 № 528 «О внесении изменений в Постановления Правительства Российской Федерации от 28 декабря 2005 г. № 819 и от 12 декабря 2015 г. № 1365», дополняющее пункт 6 и пункт 7 «Правил представления юридически- ми лицами - резидентами и индивидуальными предпринимателями - резидентами налоговым органам отчетов о движении средств по счетам (вкладам) в банках за пределами территории Российской Федерации», (Постановление Правительства Российской Федерации от 28.12.2005 № 819). Кроме того, в настоящее время подготовлен и находится на рассмотрении Государственной Думой Проект федерального закона «О внесении изменений в Федеральный закон «О валютном регулировании и валютном контроле» (в части расширения доступа российских экспортеров к продуктам экспортного страхования).

В части реализации мер поддержки экспорта транспортных услуг принят федеральный закон от 29.09.2019 № 322-Ф3 «О внесении изменений в статьи 164 и 165 части второй Налогового кодекса Российской Федерации» , предусматривающий применение налоговой ставки налога на добавленную стоимость 0 процентов на перевозку порожнего подвижного состава и контейнеров в международном сообщении. В нормативные документы приказом Министерства транспорта РФ от 18 декабря 2019 г. N 405 «Об утверждении Правил перевозок железнодорожным транспортом грузов в контейнерах и порожних контейнеров» внесены изменения в правила перевозок грузов в универсальных и специализированных контейнерах.

Для поддержки мер реализации экспорта туристических услуг принято постановление Правительства Российской Федерации от 19 декабря 2019 г. № 1719 «О внесении изменений в постановление Правительства Российской Федерации от 6 февраля 2018 г. № 105» (постановление Правительства Российской Федерации от 6 февраля 2018 г. N 105 «О реализации пилотного проекта по компенсации физическим лицам - гражданам иностранных государств суммы налога на добавленную стоимость при вывозе товаров за пределы таможенной территории Евразийского Экономического Союза»).

Реализация мер поддержки экспорта строительных услуг перешла на новый этап за счет сформированного регулярно обновляемого реестра тендеров иностранных инфраструктурных проектов, построенного на базе государственной информационной системы промышленности (ГИСП) на сайте Минпромторга России.

Одним из инструментов поддержки экспорта услуг по переработке, техническому обслуживанию и ремонту товаров стали разработанные Методические рекомендации по алгоритму действий участника внешнеэкономической деятельности по получению в таможенном органе разрешения на переработку товаров на таможенной территории, в том числе в случае использования в качестве способа идентификации иностранных товаров в продуктах их переработки, документов, содержащих сведения об использовании иностранных товаров, тех- 
нологическом процессе совершения операций по переработке, составляющих систему производственного, бухгалтерского, складского и налогового учета, размещенные на сайте $\mathrm{AO}$ «РЭЦ».

Для реализации мер финансовой поддержки экспорта услуг частным лицам и услуги в сфере культуры и отдыха приняты постановление Правительства Российской Федерации от 07.11.2019 № 1420 «О государственной поддержке организаций кинематографии, оказывающих услуги (выполняющих работы), связанные с осуществлением производства иностранными производителями аудиовизуальной продукции на территории Российской Федерации» и постановление Правительства Российской Федерации от 05.12.2019 № 1596 «О государственной поддержке проектов повышения конкурентоспособности, связанных с продвижением, сертификацией и (или) адаптацией российской продукции, в том числе содержащей результаты интеллектуальной деятельности, к требованиям внешних рынков» (с изменениями на 11 июля 2020 года).

В ноябре 2020 Председатель правительства России утвердил «дорожную карту» трансформации делового климата для новых видов предпринимательской деятельности, что поможет избавить высокотехнологичный бизнес от излишних барьеров, упростит инвестирование в передовые отрасли и способствует реализации мероприятий по совершенствованию нормативной базы и позволит устранить препятствия для использования новаций в медицине, образовании, финансовом секторе, автотранспорте, воздушных перевозках.

Конечно, на сегодня, анализируя факторы, влияющие на развитие потенциала российского экспорта услуг, нельзя не остановиться на воздействии пандемии коронавируса на весь мировой рынок, в том числе и рынок услуг.

По данным таможенной статистики за январь-сентябрь 2020 года показывают, что внешнеторговый оборот России сократился почти на $17 \%$ по сравнению январем-сентябрем 2019 года, а сальдо торгового баланса на 57 млрд. долл. США меньше, чем в обозначенный период 2019 года. Что касается сферы торговли услугами, то по данным Департамента по экономическим и социальным вопросам ООН, мировой экспорт услуг упал сильнее, на 7,6 процента в годовом исчислении за тот же период и на 7,3 процента по сравнению с предыдущим кварталом с учетом сезонных колебаний.

Правительства стран, введя в начале 2020 года повсеместные карантинные меры и другие ограничения, такие, как: ограничения на поездки, связанные с решением деловых вопросов (как внутри страны, так и за границу), ограничения на личные контакты (меры «социального дистанцирования»), временное частичное закрытие гостиничного и ресторанного бизнеса, развлекательных заведений, существенные ограничения на путешествия, а также ограничения на транспортировку грузов, ограждаю себя от распространения коронавируса, усугубили и без того прогрессирующий спад экономической активности.

Но, не смотря на принятые меры, риск ухудшения ситуации остается, т.к. уже проявляются новые вспышки заболевания, что требует вновь дополнительных мер сдерживания и дальнейшее продолжительное снижение экономической активности приводит к более серьезным, чем ожидалось, последствиям.

В этой ситуации необходимы меры диверсификации традиционных задач и видов деятельности с использование достижений цифровой экономики, как можно заметить те услуги, которые не требуют очного контакта и не имеют материальной составляющей, способные предоставляться в формате on-line, наименее подвержены влиянию ограничений, из-за пандемии. Наоборот, акцентируя внимание на новые сектора, связанные с научной, консультационной или творческой деятельностью, с научно-техническими достижениями в области цифровой экономики, расширяя возможности трансграничной электронной коммерции и цифровых платежей, используя телеконференций с деловыми партнерами по всему миру, заменяя физические документы электронными, используя транзакции с применением цифровых технологий для развития потенциала экспорта услуг, все эти действия становятся, как никогда важными для поддержания отечественной экономики и развития потенциала экспорта отечественных услуг. Несмотря на принимаемые меры, по данным Прогноза основных показателей социально-экономического развития РФ на 2020-2023 годы, большая неопределенность в отношении пути развития пандемии коронавируса COVID-19 остается основным фактором, формирующим дальнейшее развитие мировой экономики и сдерживающим оценку баланса рисков.

В международной торговле услугами - формирование межотраслевых цифровых платформ, реформирование нормативных документов осуществления трансграничных цифровых платежей, уменьшение цифрового неравенства между развитыми странами и странами с развивающейся экономикой (между разными социальными слоями внутри страны), совершенствуя защиту конфиденциальных персональных данных, противодействие цифровому протекционизму - содействия этим направлениям деятельности на государственном и межгосударственном уровне можно, не дожидаясь посткризисного периода, придать новый импульс развитию мировой торговли услугами и уменьшить социальные последствия кризиса. 


\section{ЛИТЕРАТУРА}

1. Андреева Е.Л., Малышева Е.В. Теоретические подходы к исследованию экспортного потенциала национальной экономики // Журнал экономической теории. - 2020. - Т. 17. — № 2. - С. 265

2. Шуйский В.П. Российский экспорт услуг: поиск новых драйверов роста//Внешнеторговая деятельность. — 2018. — № 5. С. 24-35.

3. Федорова 0.А., Скорлупина Ю.О., Федорова М.М. Россия на мировом рынке услуг: анализ современных тенденций // Вестник Волжского университета имени В.Н. Татищева . — 2020. - Т. 2. — № 3. - C.1-9.

4. Safari, A. and Saleh, A.S. Key determinants of SMEs' export performance: a resource-based view and contingency theory approach using potential mediators, Journal of Business \& Industrial Marketing, — 2020. — Vol. 35 No. 4, pp. 635-654.

5. Спартак А.Н. Современные трансформационные процессы в международной торговле и интересы России. - М.: ВАВТ // Издательство ИКАР, 2018. - 456 с.

6. Экспорт услуг, монография / под ред. д-ра экон. наук, проф. Г.А. Карповой. - СПб. : Изд-во СПбГЭУ, 2020. - 197 с.

7. Соколова Е.С., Поспелов В.К., Торопова Н.В., Мехдиев Э.Т. Анализ эффективности мер финансовой поддержки экспорта в России // Экономика: вчера, сегодня, завтра. 2019. Т. 9. № 6-1. С. 343-353.

8. Микрина В.Г. История возникновения и особенности развития трудовых прав человека // Евразийский юридический журнал. 2019 (129). № 2. С. $205-207$.

9. Мировое экономическое положение и перспективы: брифинг, сентябрь 2020 г., № 141. https://www.un.org/development/desa/dpad/publication/worldeconomic-situation-and-prospects-september-2020-briefing-no-141/.
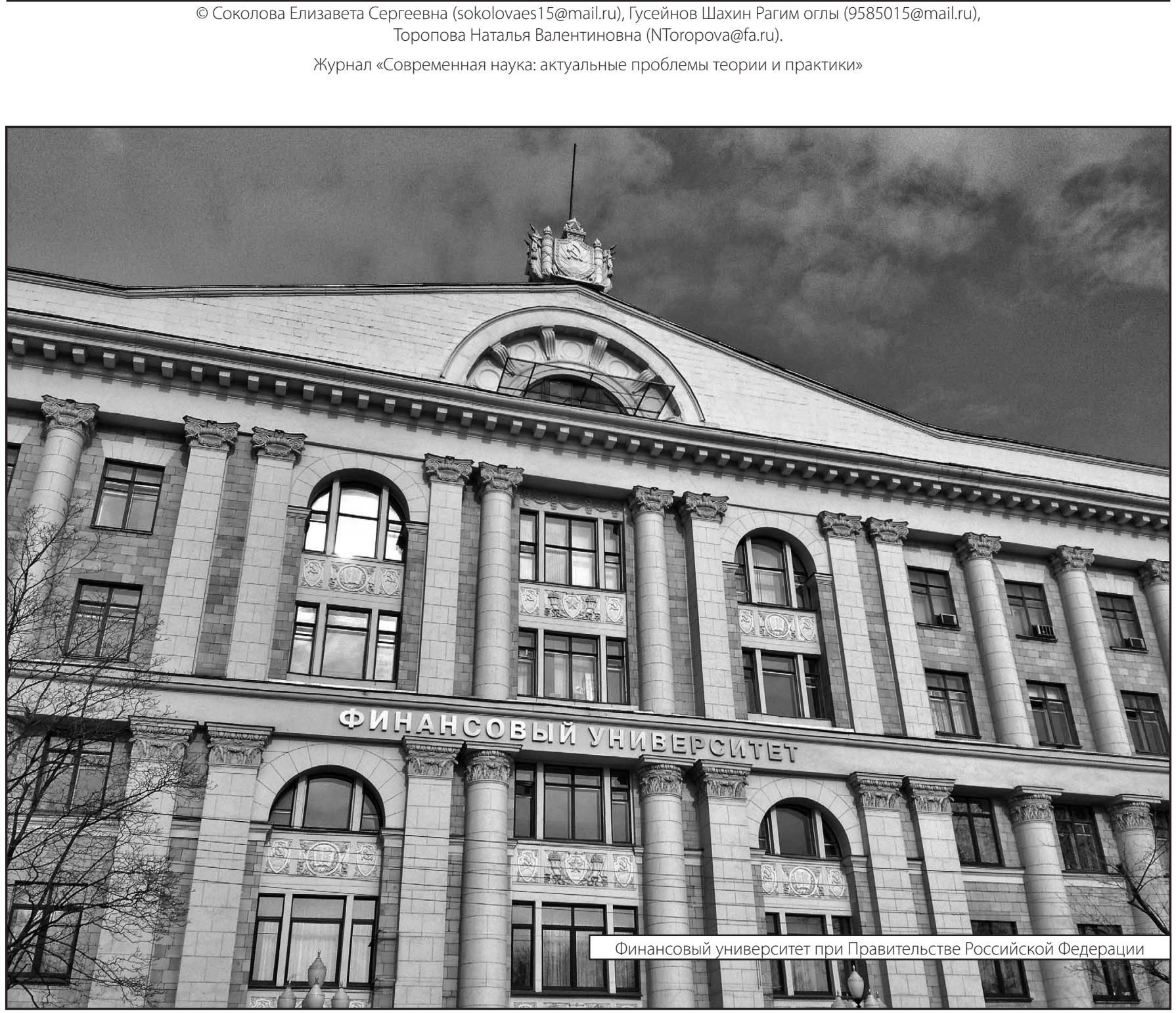